\title{
Fixed Bed Reactor Performance for Herbicide Degradation Under Solar Radiation
}

\author{
Nadia Chekir ${ }^{*}$, Djilali Tassalit ${ }^{2}$, Mounir Mellal ${ }^{1}$, Ouassila Benhabiles ${ }^{2}$, Naima Sahraoui ${ }^{1}$ \\ 1 Université des Sciences et de la Technologie Houari Boumediene (USTHB), Faculté de \\ Génie Mécanique et de Génie des Procédés, Laboratoire des Phénomènes de Transfert, \\ Bab-Ezzouar, 16111 Alger, Algéria. \\ ${ }^{2}$ Unité de Développement des Equipements Solaires. UDES /Centre de Développement des \\ Energies Renouvelables CDER, Bou- Ismail, 42004, W. Tipaza, Algéria.
}

\section{ARTICLE INFO}

Keywords:

Metribuzin

Photocatalysis

Titanium Dioxide

Wastewater Treatment

\begin{abstract}
Photocatalysis has the best potential to replace the traditional wastewater treatment techniques such as activated carbon adsorption, chemical oxidation, and biological treatment.

Photocatalysis is a combination of a catalyst semiconductor is titanium dioxide $\mathrm{TiO}_{2}$ with an ultraviolet light source as the sun. It has the added advantage of not introducing additives in the medium to be treated. However, when applied in slurry form, agglomeration of nanoparticle will lead to serious decrease in photocatalytic performance due to hinderance effect. Further, the present study has made an effort to use a support for the immobilization of catalyst for treating the pesticide polluted water by photocatalytic degradation. In the present paper, we present the performance of 2 kinds of Titanium dioxide (Commercial Media Ahlstrom and impregned $\mathrm{TiO}_{2}$ on glass) as photocatlytic support in fixed bed reactor for the degradation of Metribuzin herbicide under solar radiation. The degradation Performance was studied under various conditions such as substrate and $\mathrm{pH}$ solution. Solar photocatalytic degradation rate can reach $100 \%$ during 180 min of treatment with using $\mathrm{TiO}_{2}$ immobilized on commercial support media 1048.
\end{abstract}

\section{Introduction}

Organic chemical products such as, dyes, endocrine disruptors, pesticides and herbicides lead to serious environmental contamination. In particular, various types of pesticide are widely employed in agricultural practice. They are one of the major causes of pollution of surface and ground waters (Oyama et al., 2004). These compounds are toxic and carcinogenic in nature even at low concentration (Ozdemir, Sahinkaya, \& Onucyildiz, 2008), several of them are resistant to conventional chemical and biological treatment methods. The search for effective means of removing these compounds is of interest to regulating authorities everywhere (Kositzi et al., 2004).

Advanced oxidation processes (AOPs) have been proposed as an alternative for the treatment of this type of wastewater. Many researchers have concentrated on this goal pointing out that these processes, although making use of different reacting systems, are all characterised by the same chemical feature: production of $\mathrm{OH}$ radicals $(\bullet \mathrm{OH})$ (Malato $t$ al., 2002). Among the 
different AOPs, heterogeneous photocatalysis using $\mathrm{UV} / \mathrm{TiO}_{2}$ system appears as one of the most destructive technologies (Chekir, Laoufi, \& Bentahar, 2014; Chen, Yang, Wang, \& Lou, 2005; Gaya \& Abdullah, 2008; Herrmann, 2005). The titanium dioxide photocatalyst is widely available, inexpensive, non-toxic, and shows a relatively high chemical stability (Augugliaro, Loddo, Palmisano, \& Schiavello, 1995; Topalov, Molnar-Gabor, Kosanić, \& Abramović, 2000; Duffy et al., 2004). However due to the difficulty of nanosized photocatalysts separating fromaqueous or gaseous pollutants after reactions in suspended reactor and to avoid the filtration step, fixed-bed system appeared in which the photocatalysts were immobilized on the walls of the reactor, on the supported substrates, or around the light source (Xu et al., 2008).

The aim of the present work is to study the efficiency of two catalytic supports on the solar photocatalysis of metribuzin. In order to determine the optimal degradation conditions of this organic pollutant different parameters influencing photocatalysis were considered.

\section{Material and Methods}

2.1 Chemical and reagents

a) Pollutant

Selected pestecide used in this study was the metribuzin $\mathrm{C}_{8} \mathrm{H}_{14} \mathrm{~N}_{4} \mathrm{OS}$ (fig.1.) with a molecular weight of $214.32(\mathrm{~g} / \mathrm{mol})$. Metribuzin is one of the nitrogen-containing herbicides in the family of triazine herbicides, is registered for the control of annual broadleaf weeds and grassy weeds that infest various crops, including potatoes, tomatoes ... etc.<smiles>CSc1nnc(C(C)(C)C)c(=O)n1N</smiles>

Figure 1: Chemical structure of metribuzin

Metribuzin degradation was evaluated by measuring the absorbance with spectrophotometer UV-VISIBLE, type Shimatzu UV1800. The maximum absorption band was located at 293 nm. A correlation curve between Metribuzin concentration and the absorption was preestablished.

\section{b) photocatalysts}

A commercially available titanium dioxide PC-500 was used as a photocatalyst produced by Millenium Inorganic Chemicals. This photocatalyst is in $99 \%$ anatase form with BET specific surface area of $320 \mathrm{~m}^{2} \cdot \mathrm{g}^{-1}$ and particle diameter betweem 5 and $10 \mathrm{~nm}$. In this study, we used titanium dioxide in two forms: $\mathrm{TiO}_{2} \mathrm{PC}-500$ supported on cellulose "média 1048 " and $\mathrm{TiO}_{2}$ PC 500 Millennium impregnated and fixed on glass.

\subsection{Photoreactor}

All the experiments were performed under natural sun light in a step photoreactor (Fig.2) specially developed for photocatalytic application installed at the Solar Equipment Development Unit (UDES) on the north of Algeria (latitude $36^{\circ} .39^{\prime}$; longitude $2^{\circ} .42^{\prime}$ ) using natural sun-light irradiation. Solar ultraviolet radiation (U.V.) was measured by global UV radiometer (KIPP\&ZONEN, CMP11) mounted on a plat form tilted $36^{\circ}$ as the reactor. 
The solar photocatalytic reactor used in this experiment consists of several parts: a tank, a pump, a spillway at the top and steps. The reactor was made of three (03) regular glass steps of the same dimensions $(40 \times 20 \times 1 \mathrm{~cm})$ covered with the photocatalytic media or impregned solution (corresponding to $1.1 \mathrm{mg} / \mathrm{cm}^{2}$ ).

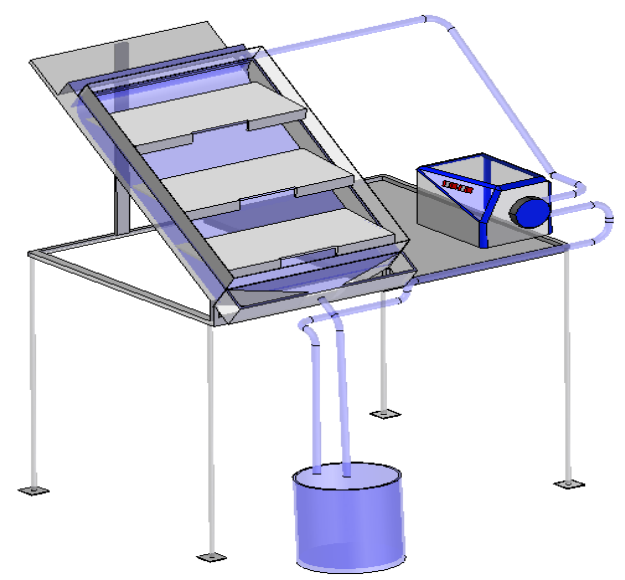

Figure.2. Experimental set-up

\section{Results and discussion}

\subsection{Effect of $p H$ solution}

$\mathrm{pH}$ is an important parameter in photocatalysis, which influences the surface charge of $\mathrm{TiO}_{2}$ and therefore adsorption of the pollutant. The $\mathrm{pH}$ solution was adjusted by adding $\mathrm{NaOH}$ or $\mathrm{H}_{2} \mathrm{SO}_{4}$.

The role of $\mathrm{pH}$ on the rate of photocatalytic degradation was studied in the $\mathrm{pH}$ range 3-9.5 at constant pesticide concentration $\left(10 \mathrm{mg} \mathrm{L}^{-1}\right)$.

The obtained Results for the two kind of photocatalyst support, with varying $\mathrm{pH}$ from 3 to 9.5, were illustrated in Fig. 3. Table 1 summarizes the calculated $\mathrm{k}_{\text {app }}$ and $\mathrm{t}_{1 / 2}$.
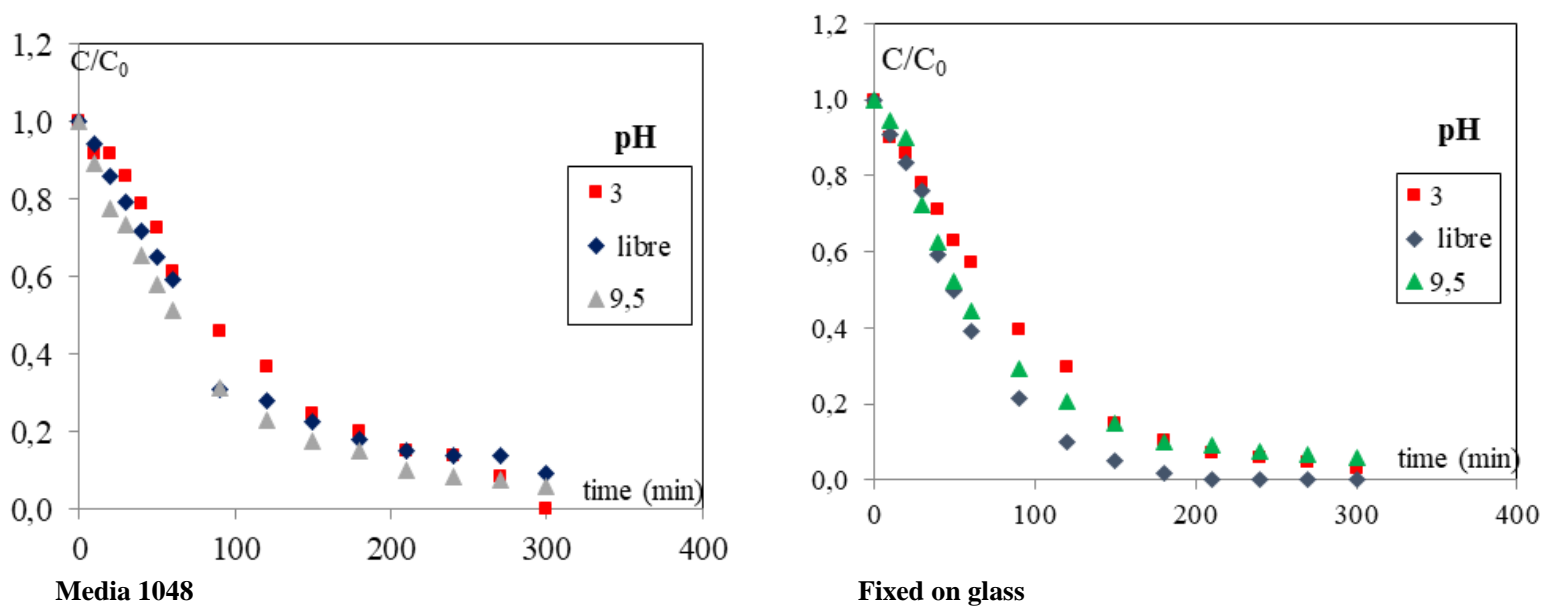

Figure 3. Temporal evolution of metribuzin elimination rate for different $\mathrm{pH}$. $\mathrm{CMET}_{\mathrm{MET}}=10 \mathrm{mgL}^{-1}$

The obtained results in fig. 3 show that after 300 minutes of photocatalytic treatment, the metribuzin removal is around $97 \%$ and $94 \%$ for acidic and basic $\mathrm{pH}$ respectively when the $\mathrm{TiO}_{2}$ photocatalyst is supported on tissues "media 1048". The results are almost similar when the catalyst is supported on glass plates. While for the free $\mathrm{pH}$ (7.0-7.2), the degradation is complete with a yield of $100 \%$ for both types of cellulosic support. 
Table 1.

Value of kinetic constants, times of half reaction for different $p H$ solution for 2 kind of catalytic support.

\begin{tabular}{ccccccc}
\hline & $\mathrm{pH}$ & $\begin{array}{c}\mathrm{k} \\
\left(\mathrm{min}^{-1}\right)\end{array}$ & $\mathrm{R} 2$ & $\mathrm{X} \%$ & $\begin{array}{c}\mathrm{t}_{1 / 2} \\
(\mathrm{~min})\end{array}$ & $\begin{array}{c}\mathrm{r}_{0} \\
\left(\mathrm{mg}^{-L^{-1}} \cdot \mathrm{min}^{-1}\right)\end{array}$ \\
\hline \multirow{3}{*}{ Media 1048 } & 3 & 0.009 & 0.99 & 97 & 77 & 0.03 \\
& Free & 0.015 & 0.99 & 100 & 46 & 0.11 \\
\multirow{5}{*}{ Glass } & 9.5 & 0.013 & 0.98 & 94 & 53 & 0.12 \\
& 3 & 0.006 & 0.99 & 95 & 87 & 0.02 \\
& Free & 0.010 & 0.99 & 100 & 83 & 0.06 \\
& 9.5 & 0.011 & 0.99 & 94 & 63 & 0.10 \\
\hline
\end{tabular}

\subsection{Effect of Metribuzin concentration}

To confirm the effectiveness photocatalysis, it is also necessary to study the photocatalytic degradation rate for different initial pollutant concentrations.

The effect of the initial metribuzin concentration on the rate of pollutant degradation was studied by varying the initial concentration from 2.5 to $20 \mathrm{mg} / \mathrm{L}$.

All experiments were carried out with both types of photocatalytic support: $\mathrm{TiO}_{2}$ PC-500 supported on cellulosic (media 1048) or impregned impregnated on glass plates.
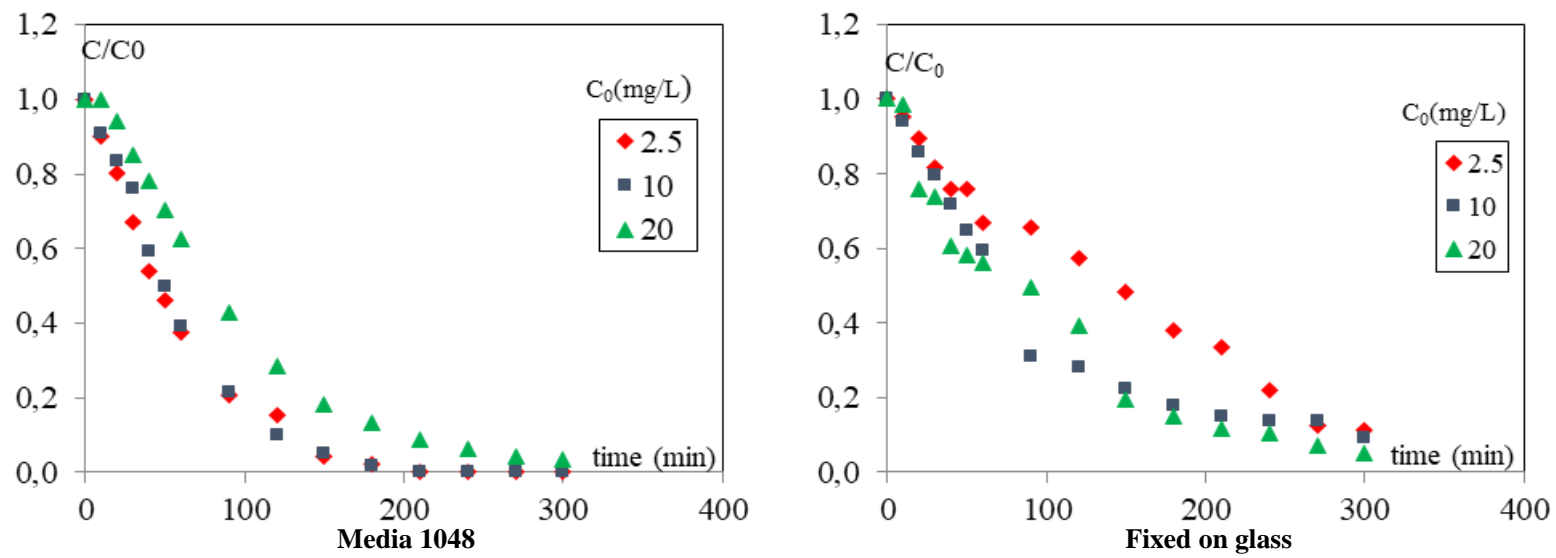

Figure 4. Temporal evolution of Metribuzin elimination rate for different concentration

The obtained results (Fig.4) show that the Metribuzin elimination rate on media 1048 photocatalytic support is greater when the pollutant concentration is lower, whereas for the second glass support the influence of the pollutant concentration is not very noticed.

Table2.

Value of kinetic constants, times of half reaction for differents pollutant concentrations

\begin{tabular}{ccccccc}
\hline \multirow{6}{*}{ Media 1048 } & $\begin{array}{c}\mathrm{C}_{0} \\
(\mathrm{mg} / \mathrm{L})\end{array}$ & $\begin{array}{c}\mathrm{k} \\
\left(\mathrm{min}^{-1}\right)\end{array}$ & $\mathrm{R}^{2}$ & $\begin{array}{c}\mathrm{X} \\
\%\end{array}$ & $\begin{array}{c}\mathrm{t}_{1 / 2} \\
(\mathrm{~min})\end{array}$ & $\begin{array}{c}\mathrm{r}_{0} \\
\left(\mathrm{mg} . \mathrm{L}^{-1} \cdot \mathrm{min}^{-1}\right)\end{array}$ \\
\hline \multirow{6}{*}{ Glasse } & 2.5 & 0.017 & 0.99 & 100 & 41 & 0.04 \\
& 10 & 0.015 & 0.99 & 100 & 46 & 0.15 \\
& 20 & 0.007 & 0.97 & 96 & 96 & 0.14 \\
& 2.5 & 0.006 & 0.99 & 95 & 110 & 0.02 \\
& 10 & 0.008 & 0.99 & 90 & 82 & 0.08 \\
\end{tabular}


According to Table 2, metribuzin degradation follows the pseudo-first order kinetic model. The apparent rate constants for each pollutant concentration were determined by linear regression form $\left(\ln \left(\mathrm{C} / \mathrm{C}_{0}\right)\right.$ versus time $)$. We note that these values increase slightly for the glass photocatalytic support, on the other hand, for the media 1048 the apparent constant decreases by increasing the initial concentration of pollutant.

\subsection{Comparative study}

A comparative study of the photocatalytic degradation of Metribuzin on the two photocatalytic supports: the $\mathrm{TiO}_{2}$ Tissue media 1048 and the $\mathrm{TiO}_{2}$ fixed on the glass plates is presented. Figure 5 shows the kinetics of metribuzin degradation under the same optimal operating conditions, namely: $\mathrm{Q}=17.7 \mathrm{~mL} / \mathrm{s}, \mathrm{C}_{0}=10 \mathrm{mg} / \mathrm{L}$ and free $\mathrm{pH}$.

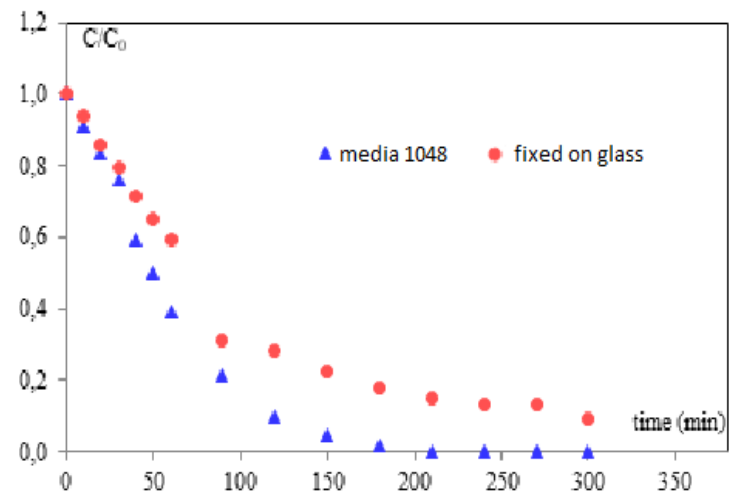

Figure 5.

Temporal evolution of Metribuzin elimination rate for both catalytic support under optimal conditions $(\mathrm{C} 0=10 \mathrm{mg} / \mathrm{L}$, free $\mathrm{pH} \mathrm{Q}=17.7 \mathrm{~mL} / \mathrm{s})$

Figure 5 shows that the metibuzin elimination is more important with using $\mathrm{TiO}_{2}$ media 1048 as a photocatalytic support. The degradation is complete after only 180 minutes of treatment while on the glass support, the rate of abatement does not exceed $90 \%$ after 300 minutes of treatment. Table 3 summarizes the different kinetic constants.

Table 3.

Value of kinetic constants, half-reaction times for both catalytic support

\begin{tabular}{lccccc}
\hline & $\begin{array}{c}\mathrm{k} \\
\left(\mathrm{min}^{-1}\right)\end{array}$ & $\mathrm{X} \%$ & $\mathrm{R}^{2}$ & $\begin{array}{c}\mathrm{t}_{1 / 2} \\
(\mathrm{~min})\end{array}$ & $\begin{array}{c}\mathrm{r}_{0} \\
\left(\mathrm{mg} \cdot \mathrm{L}^{-1} \cdot \mathrm{min}^{-1}\right)\end{array}$ \\
\hline Media 1048 & 0.0150 & 100 & 0.99 & 46 & 0.150 \\
Glass & 0.0084 & 90 & 0.99 & 83 & 0.084 \\
\hline
\end{tabular}

\section{Conclusion}

The degradation of metribuzin on $\mathrm{TiO}_{2}$ fixed bed was investigated under the solar irradiation. The results show that the photocatalytic process $\mathrm{U} . \mathrm{V} . / \mathrm{TiO}_{2}$ seems to be very efficient on the removal of herbicide resistant to conventional techniques. Solar photocatalytic degradation rate can reach $100 \%$ during $180 \mathrm{~min}$ of treatment with using $\mathrm{TiO}_{2}$ immobilized on commercial support media 1048

This process was also developed using an impregnated $\mathrm{TiO}_{2}$ on glass plates, around $90 \%$ of degradation for more time (300min).

For the similar degradation, the solar photocatalysis in fixed bed reactor can be recommended to avoid the filtration step, for its low energetic cost and a very good efficiency. 


\section{Acknowledgments}

This work was supported by Solar Equipment Development Unit (UDES).

\section{References}

Augugliaro, V., Loddo, V., Palmisano, L., \& Schiavello, M. (1995). Performance of heterogeneous photocatalytic systems: influence of operational variables on photoactivity of aqueous suspension of TiO2. Journal of catalysis, 153(1), 32-40.

Duffy, E. F., Al Touati, F., Kehoe, S. C., McLoughlin, O. A., Gill, L. W., Gernjak, W., ... \& Reed, R. H. (2004). A novel TiO2-assisted solar photocatalytic batch-process disinfection reactor for the treatment of biological and chemical contaminants in domestic drinking water in developing countries. Solar Energy, 77(5), 649-655.

Gaya, U. I., \& Abdullah, A. H. (2008). Heterogeneous photocatalytic degradation of organic contaminants over titanium dioxide: a review of fundamentals, progress and problems. Journal of photochemistry and photobiology C: Photochemistry reviews, 9(1), 1-12.

Herrmann, J. M. (2005). Heterogeneous photocatalysis: state of the art and present applications In honor of Pr. RL Burwell Jr.(1912-2003), Former Head of Ipatieff Laboratories, Northwestern University, Evanston (Ill). Topics in catalysis, 34(1-4), 49-65.

Chekir, N., Laoufi, N. A., \& Bentahar, F. (2014). Spiramycin photocatalysis under artificial UV radiation and natural sunlight. Desalination and Water Treatment, 52(34-36), 68326839.

Chen, Y., Yang, S., Wang, K., \& Lou, L. (2005). Role of primary active species and TiO2 surface characteristic in UV-illuminated photodegradation of Acid Orange 7. Journal of photochemistry and photobiology A: chemistry, 172(1), 47-54.

Kositzi, M., Antoniadis, A., Poulios, I., Kiridis, I., \& Malato, S. (2004). Solar photocatalytic treatment of simulated dyestuff effluents. Solar Energy, 77(5), 591-600.

Malato, S., Blanco, J., Cáceres, J., Fernández-Alba, A. R., Agüera, A., \& Rodrıguez, A. (2002). Photocatalytic treatment of water-soluble pesticides by photo-Fenton and TiO2 using solar energy. Catalysis Today, 76(2-4), 209-220.

Oyama, T., Aoshima, A., Horikoshi, S., Hidaka, H., Zhao, J., \& Serpone, N. (2004). Solar photocatalysis, photodegradation of a commercial detergent in aqueous $\mathrm{TiO} 2$ dispersions under sunlight irradiation. Solar Energy, 77(5), 525-532.

Ozdemir, C., Sahinkaya, S., \& Onucyildiz, M. (2008). Treatment of pesticide wastewater by physicochemical and Fenton processes. Asian Journal of Chemistry, 20(5), 3795.

Topalov, A., Molnar-Gabor, D., Kosanić, M., \& Abramović, B. (2000). Photomineralization of the herbicide mecoprop dissolved in water sensitized by TiO2. Water research, 34(5), 1473-1478.

Xu, J., Ao, Y., Fu, D., Lin, Y., Shen, X., Yuan, C., \& Yin, Z. (2008). Photocatalytic activity on TiO2-coated side-glowing optical fiber reactor under solar light. Journal of Photochemistry and Photobiology A: Chemistry, 199(2-3), 165-169. 